\title{
Plataforma Blackboard: Una herramienta para el proceso de Enseñanza-Aprendizaje
}

\author{
Blackboard Platform: A tool for the Teaching Learning process \\ Claudia Liliany Aliaga Meléndez ${ }^{1}$ \\ https://orcid.org/0000-0003-1240-9455 \\ Universidad César Vallejo, Perú \\ Oscar Melanio Dávila Rojas ${ }^{2}$ \\ https://orcid.org/0000-0001-6915-8373 \\ Universidad César Vallejo, Perú
}

Recibido: 04-02-2021

Aceptado: 27-04-2021

\section{Cita Recomendada}

Aliaga, C. L. y Dávila, O. M. (2021). La plataforma Blackboard: una herramienta para el proceso de enseñanza-aprendizaje. Hamut'ay, 8(1), 42-58. http://dx.doi.org/10.21503/hamu.v8i1.2237

\section{Resumen}

La utilización de diferentes plataformas virtuales en el campo educativo para garantizar el aprendizaje remoto, se ha convertido en una experiencia novedosa para instituciones que recién incursionan en esta modalidad de enseñanza-aprendizaje. El proceso generó cambios importantes y acrecentó expectativas en docentes y estudiantes. Se apuesta por el involucramiento responsable de los estudiantes en dicho proceso, participando activamente en actividades de aprendizaje individual o colaborativo. Este artículo explora la perspectiva teórica que asumen los especialistas interesados en el tema, bajo un enfoque descriptivo, con el método de revisión sistemática, durante el periodo del 2015 al 2020, información recopilada de revistas indexadas y de repositorios institucionales. La información fue examinada mediante análisis de contenido que permitió rastrear la importancia que se da a la plataforma en el proceso de enseñanza-aprendizaje, bajo la modalidad a distancia. Cabe señalar que juega un papel importante la predisposición del docente para diseñar o estructurar el contenido de su curso, y que en ese proceso la plataforma Blackboard le ofrezca una gama de herramientas que le ayudan a implementar los contenidos curriculares con una dosis de atractivo para despertar el interés de los estudiantes. Así, se logra un mejor desempeño en la tarea pedagógica del docente, como en el logro de la competencia de la experiencia curricular. Es evidente que el docente debe recibir una capacitación previa orientada a conseguir que cuanto planifique en la plataforma sirva para lograr el objetivo académico y, como consecuencia de ello, las actividades propuestas garanticen un aprendizaje significativo.

Palabras clave: Aprendizaje en línea, aprendizaje colaborativo, educación a distancia, plataforma virtual.

1. Estudiante del Doctorado en educación de la Universidad César Vallejo-SP, Magíster en Psicología Educativa, Licenciada en educación Secundaria, especialidad de Ciencias Sociales-Educación Intercultural. Estudiante adscrita al proyecto PIPD, Innovación docente y uso de las Tecnologías de la Información y Comunicación en el proceso de enseñanza-aprendizaje. E-mail: claudialiliany@gmail.com 2. Doctor en Ciencias de la Educación, Magíster en Docencia y Gestión Educativa, Licenciado en Lengua y Literatura, Abogado. Especialista en Metodología de la Investigación. Docente del Doctorado en Educación, modalidad Semipresencial, en la EPG de la Universidad César Vallejo. Docente adscrito al programa de Mentoría UCV-SP. E-mail: oscarmelanio@yahoo.es 


\section{Abstract}

The use of different virtual platforms in the educational field to guarantee remote learning has become a new experience for institutions that are just entering this teaching-learning modality. The process generated important changes and raised expectations among teachers and students. It is committed to the responsible involvement of students in this process, actively participating in individual or collaborative learning activities. This article explores the theoretical perspective assumed by specialists interested in the subject, under a descriptive approach, with the method of systematic review, during the period from 2013 to 2020, information collected from indexed journals and institutional repositories. The information was examined through content analysis that allowed tracking the importance given to the platform in the teaching-learning process, under the distance modality. It should be noted that the teacher's predisposition to design or structure the content of their course plays an important role, and that in this process the Blackboard platform offers them a range of tools that help them to implement the curricular content with a dose of attractiveness to arouse the interest of students. Thus, a better performance in the pedagogical task of the teacher is achieved of the competence of the curricular experience.

It is evident that the teacher must receive prior training aimed at ensuring that what has been planned on the platform serves to achieve the academic objective and, as a consequence, the proposed activities guarantee meaningful learning.

Keywords: online learning, collaborative learning, distance education, virtual platform.

\section{Introducción}

En el presente siglo, las diversas plataformas virtuales son exploradas en distintas actividades, especialmente en educación superior, que encuentra en estas al aliado ideal para desarrollarse y ampliar la cobertura de su servicio. En estos días, muchas organizaciones educativas (públicas y privadas) recurren a las plataformas como medio para la interacción académica entre estudiantes y docentes. Blackboard es una de ellas, que por su flexibilidad y funcionalidad permite a los docentes planificar actividades de aprendizaje; facilita la interacción y, al mismo tiempo, fomenta el trabajo autónomo y autorregulado. El uso de esta plataforma se convierte en una nueva gran experiencia para toda la comunidad universitaria, garantizando la continuidad del servicio educativo. El progreso de las tecnologías web 4.0 que brindan un procedimiento más inteligente y predictivo es el avance reciente en las plataformas virtuales (Piedra et al., 2019). Esto permite realizar acciones idóneas en la implementación del aula virtual, de manera que gradualmente se produzca la adaptación al cambio y la inmersión en las bondades de la tecnología. Se ha producido la evolución de la web 1.0 a la web 4.0 y hay que tener en cuenta que esta última apareció a inicios del 2010 como resultado de un proceso industrial caracterizado por la producción de máquinas y productos interconectados en forma digital (Iglesias y Soca, 2017).

La incursión en una educación no presencial mediante una plataforma virtual, en forma sistemática, con recursos pedagógicos, con el acompañamiento de un tutor propician una instrucción independiente y la acción cooperativa de los participantes (García, 2020). Esto no es posible sin la preparación oportuna de los docentes, quienes necesitan usar de manera eficiente las herramientas tecnológicas y plataformas. Se requiere, por tanto, la ejecución de planes de capacitación para el diseño de actividades pedagógicas motivadoras que deriven en aprendizajes significativos (Valenzuela y Pérez, 2015). Con ello se permitirá una mayor familiaridad con la plataforma virtual. Los conocimientos que desarrolle el docente en talleres o capacitaciones incrementarán su eficiencia en el uso de la plataforma y la preparación adecuada de sus actividades pedagógicas. A su vez, los estudiantes encontrarán más atractiva e interesante su participación en los retos 
propuestos, lo que beneficiará en su aprendizaje en las clases sincrónicas. Durante estas, es posible también acceder a nuevas y variadas herramientas tecnológicas que otorguen dinamismo al proceso de aprendizaje-enseñanza (Álvarez et al., 2020). Tanto docentes como estudiantes reconocen la importancia y utilidad de las plataformas en el proceso pedagógico (Martínez y Jiménez, 2020), aun cuando a veces el trabajo se puede ver afectado por las fallas técnicas asociadas a la conectividad, sin embargo, se observa que, a pesar de que el estudiante debería mejorar su participación en la plataforma virtual, e interactuar activamente con el docente y los demás participantes, todavía no se compromete el uso óptimo de la herramienta y se descuida las actividades programadas.

Por otro lado, la cuarentena en el Perú en el contexto de la Covid-19 obligó a una generalización en el uso de plataformas virtuales para garantizar el servicio educativo en forma remota y puso a prueba a docentes y estudiantes. Los docentes tuvieron que desarrollar competencias tecnológicas para realizar su trabajo y debieron adaptarse a una forma de trabajo que no tenían pensado y para la que no estaban preparados. Sin embargo, con las dificultades que representó para educadores y educandos, el reto se sobrellevó, descubrió habilidades (en docentes y estudiantes), falencias (en el dominio metodológico de los docentes) y malos hábitos (en estudiantes). A pesar de ello, la nueva experiencia permitió comprobar que se puede aprender y desarrollar competencias mediante el aprendizaje remoto.

Cabe resaltar que la tecnología tiene un impacto poderoso en una sesión de aprendizaje virtual, provoca cambios significativos en las estrategias de enseñanza-aprendizaje (Hernández y Tecpan, 2017). La incorporación de la tecnología en el aprendizaje genera cambios importantes en docentes y estudiantes, y eso es más importante que los rechazos iniciales producto del conflicto generado por la innovación pedagógica.

Este estudio abre las puertas al debate y la reflexión sobre esta nueva forma de enseñanza, ya que ha llegado para quedarse como una buena alternativa para las instituciones de educación que brindan así la oportunidad de estudiar salvando inconvenientes de traslado al ambiente físico de una casa de estudios. Desde la comodidad de su hogar, los estudiantes, pueden conectarse a su aula virtual y participar en las actividades de aprendizaje propuestas por el docente tutor. El mayor reto es para este último, que tiene la responsabilidad de diseñar actividades interactivas y motivadoras que promuevan la reflexión e indagación constante. Como explica Savio (2020), además de atractivas, estas actividades propiciarán la interacción y participación constante de los estudiantes. Cabe indicar que, en la construcción de aprendizajes, hay que garantizar el desarrollo de competencias, solo así el aprendizaje será significativo.

Para despertar el interés y desarrollar competencias es necesario dar pautas claras y precisas de las actividades y los productos a elaborar dentro de estas plataformas. La culminación o entrega de estos precisa de una retroalimentación constructiva y enriquecedora que motive al estudiante a superar sus dificultades. Las instrucciones son atractivas cuando muestran el camino claro y seguro hacia el aprendizaje; van acompañadas de nuevos contenidos que ayudan a comprender al estudiante aquello que se le propone como reto de aprendizaje. Si lo anterior no es así o no se brinda en forma oportuna la retroalimentación, se genera incertidumbre y desánimo que afectan el proceso de aprendizaje (Aguilar, Alejo \& Ayala, 2020). En tal caso, el estudiante queda con la sensación de no haber resuelto sus interrogantes. El buen docente es aquel que se preocupa por satisfacer todas las expectativas de los estudiantes que se hallan al otro lado de la red; aquel que muestra predisposición a capacitarse en el manejo de las plataformas virtuales. Pero eso no basta, sino que es necesario que las autoridades educativas inviertan en capacitaciones que conlleven al óptimo desempeño de su personal (Lora, 2019). Así fortalecen el capital intelectual y logran el desempeño eficiente de su personal.

Hay estudiantes que desconocen el propósito de la plataforma virtual, y no entienden que esta herramienta permite el intercambio democrático y respetuoso de ideas; el desarrollo de com- 
petencias; y propicia el trabajo colaborativo y la construcción de saberes (De la Cruz et al., 2020). Dicho desconocimiento se manifiesta en desinterés e incumplimiento de las actividades planificadas, situación que se agrava cuando el docente no está familiarizado con el manejo, características y beneficios de una plataforma virtual (Mora et al., 2018). Teniendo en cuenta lo anterior, se recomienda la ineludible capacitación a los docentes, como estrategia para asegurar su interacción óptima con los estudiantes durante el desarrollo de las actividades de aprendizaje (De la Iglesia, 2019). De esta manera se logrará que el uso de la plataforma virtual incida en el aprendizaje y el docente estructure adecuadamente los contenidos; ello, sin duda, aumenta la expectativa de los estudiantes, los compromete con las actividades y los involucra positivamente en sus aprendizajes. Por lo que en este estudio se tiene como objetivo describir y explicar las características, funcionabilidad, uso, recursos, ventajas y desventajas que posee la plataforma Blackboard de manera general y específica como una herramienta en el proceso de enseñanza-aprendizaje.

\section{Método}

Para la búsqueda de la información se usó una revisión exploratoria directa, como artículos cien- tíficos, artículos de periódicos digitales y revistas científicas en bases de datos como Scielo, Dialnet, Redalyc, SCOPUS y Web of Science. La exploración se efectuó en Google Académico, Ask, Bing, libros y tesis en los repositorios de universidades reconocidas. En la figura 1 se muestra el diagrama de flujo del proceso de búsqueda y selección.

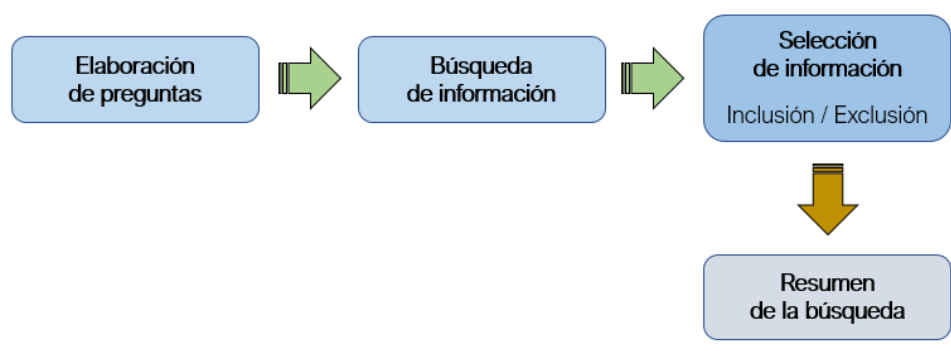

Figura 1. Proceso para la revisión sistemática. Fuente. Elaboración propia (2021).

La revisión de la literatura para este estudio abarcó publicaciones comprendidas entre 2013 y 2020. Inicialmente se consultó 100 artículos y, mediante la revisión sistemática de estos, se realizó exclusiones de forma preliminar considerando las palabras clave: aprendizaje, aprendizaje en línea, aprendizaje colaborativo, educación a distancia y plataformas virtuales. El proceso de exclusión finalizó con la selección de 32 artículos y 2 tesis, clasificados de acuerdo con el interés de la investigación. Estos se describen en la tabla 1.

Tabla 1. Estudios incluidos en la revisión sistemática exploratoria

\begin{tabular}{|c|c|c|c|c|c|c|c|}
\hline $\begin{array}{l}\text { Motor de } \\
\text { búsqueda }\end{array}$ & $\begin{array}{c}\text { Keywords } \\
\text { (palabras } \\
\text { clave) }\end{array}$ & $\begin{array}{c}\text { Año - título } \\
\text { de la } \\
\text { revista }\end{array}$ & $\begin{array}{c}\text { Tipo de } \\
\text { publicación }\end{array}$ & $\begin{array}{c}\text { Título del artículo / } \\
\text { publicación }\end{array}$ & Autor & País & Lengua \\
\hline Redalyc.org & On line learning & $\begin{array}{l}2013 \text { - } \\
\text { Educación y } \\
\text { Educadores }\end{array}$ & Articulo & $\begin{array}{l}\text { Aprendizaje } \\
\text { autorregulado a través } \\
\text { de la plataforma virtual } \\
\text { Moodle }\end{array}$ & $\begin{array}{l}\text { Valenzuela, B., } \\
\text { Peréz, M }\end{array}$ & Colombia & Español \\
\hline $\begin{array}{l}\text { Google } \\
\text { Scholar }\end{array}$ & $\begin{array}{l}\text { distance } \\
\text { education }\end{array}$ & $\begin{array}{l}2020- \\
\text { Innovaciones } \\
\text { educativas }\end{array}$ & Articulo & $\begin{array}{l}\text { La docencia en el nivel } \\
\text { de posgrado en el } \\
\text { contexto } \\
\text { de virtualización de } \\
\text { emergencia. } \\
\text { Aprendizajes y desafíos } \\
\text { para el futuro en la } \\
\text { experiencia de la } \\
\text { Universidad Nacional } \\
\text { de Tres de Febrero }\end{array}$ & $\begin{array}{l}\text { Álvarez, M., } \\
\text { Fernández, N., } \\
\text { García, P., Grandoli, } \\
\text { E. y Pérez C. }\end{array}$ & Argentina & Español \\
\hline $\begin{array}{l}\text { Google } \\
\text { Scholar }\end{array}$ & $\begin{array}{l}\text { Plataforma } \\
\text { educativa }\end{array}$ & $\begin{array}{l}\text { 2020- Páginas } \\
\text { de educación }\end{array}$ & Articulo & $\begin{array}{l}\text { La plataforma moodle en } \\
\text { la alfabetización } \\
\text { académica: uso del aula } \\
\text { virtual en un taller de } \\
\text { lectura y escritura }\end{array}$ & Savio, K. & Argentina & Español \\
\hline
\end{tabular}




\begin{tabular}{|c|c|c|c|c|c|c|c|}
\hline $\begin{array}{l}\text { Google } \\
\text { Scholar }\end{array}$ & $\begin{array}{l}\text { Plataforma } \\
\text { virtual }\end{array}$ & $\begin{array}{l}\text { 2020- } \\
\text { Recimundo }\end{array}$ & Articulo & $\begin{array}{l}\text { Las plataformas virtuales } \\
\text { para fomentar } \\
\text { aprendizaje colaborativo } \\
\text { en los estudiantes del } \\
\text { bachillerato }\end{array}$ & $\begin{array}{l}\text { Tomalá, M., Gallo, } \\
\text { G., Mosquera, J. y } \\
\text { Chancusig, J. }\end{array}$ & Ecuador & Español \\
\hline Dialnet & LEARNING & $\begin{array}{l}2020- \\
\text { Innoeduca. } \\
\text { international } \\
\text { journal of } \\
\text { technology } \\
\text { and } \\
\text { educational } \\
\text { innovation }\end{array}$ & Articulo & $\begin{array}{l}\text { Development of learning } \\
\text { objects for the learning } \\
\text { of data structures }\end{array}$ & $\begin{array}{l}\text { Aguilar, I., Alejo, V. } \\
\text { y Ayala, J. }\end{array}$ & México & English \\
\hline Scielo & $\begin{array}{l}\text { Collaborative } \\
\text { Learning, } \\
\text { Moodle }\end{array}$ & $\begin{array}{l}2020 \text {-Journal } \\
\text { of e-learning } \\
\text { and } \\
\text { knowledge } \\
\text { society }\end{array}$ & Articulo & $\begin{array}{l}\text { Technology to enable } \\
\text { new paradigms of } \\
\text { teaching/learning in } \\
\text { mathematics: the digital } \\
\text { interactive storytelling } \\
\text { case }\end{array}$ & $\begin{array}{l}\text { Albano, G., } \\
\text { Coppala, C., Dello, } \\
\text { U., Giuseppe, F., } \\
\text { Pierri, A., Polo, M. }\end{array}$ & Italy & English \\
\hline $\begin{array}{l}\text { Web of } \\
\text { Science }\end{array}$ & $\begin{array}{l}\text { Interfaz } \\
\text { Usuario- } \\
\text { Computador }\end{array}$ & $\begin{array}{l}\text { 2020-CES- } \\
\text { Medicina }\end{array}$ & Articulo & $\begin{array}{l}\text { Ventajas, desventajas y } \\
\text { ocho recomendaciones } \\
\text { para la educación médica } \\
\text { virtual en tiempos de } \\
\text { COVID-19 }\end{array}$ & Vásquez, D. & Colombia & Español \\
\hline $\begin{array}{l}\text { Google } \\
\text { Scholar }\end{array}$ & $\begin{array}{l}\text { Blackboard } \\
\text { Collaborate }\end{array}$ & $\begin{array}{l}\text { 2019-Digital } \\
\text { education }\end{array}$ & Articulo & $\begin{array}{l}\text { Valoración y uso de la } \\
\text { plataforma Blackboard } \\
\text { Collaborate en una } \\
\text { universidad a distancia: } \\
\text { estudio de caso sobre las } \\
\text { prácticas declaradas de } \\
\text { docentes del Grado de } \\
\text { Psicología }\end{array}$ & $\begin{array}{l}\text { Villalón, R., Luna, } \\
\text { M. y García, A. }\end{array}$ & España & Español \\
\hline $\begin{array}{l}\text { Revista } \\
\text { UCV } \\
\text { Eduser }\end{array}$ & Virtual platform & $\begin{array}{l}\text { 2020-Journal } \\
\text { Eduser }\end{array}$ & Articulo & $\begin{array}{l}\text { Digital Portfolio in The } \\
\text { Development of } \\
\text { Documentary } \\
\text { Competence in } \\
\text { University Students }\end{array}$ & $\begin{array}{l}\text { Cornejo, J., } \\
\text { Limaymanta, C., } \\
\text { Mezarina, R. y } \\
\text { Gálvez, B. }\end{array}$ & Lima & English \\
\hline $\begin{array}{l}\text {-@ tic. } \\
\text { revista }\end{array}$ & $\begin{array}{l}\text { Educación a } \\
\text { distancia }\end{array}$ & $\begin{array}{l}\text { 2018-@ tic. } \\
\text { revista }\end{array}$ & Articulo & $\begin{array}{l}\text { Aprendizaje cooperativo } \\
\text { a través de las nuevas } \\
\text { tecnologías: Una } \\
\text { revisión }\end{array}$ & $\begin{array}{l}\text { Herrada, R. y Baños, } \\
\text { R. }\end{array}$ & España & Español \\
\hline Scielo & $\begin{array}{l}\text { Aprendizaje } \\
\text { colaborativo }\end{array}$ & 2017- Scielo & Articulo & $\begin{array}{l}\text { Aula invertida mediada } \\
\text { por el uso de plataformas } \\
\text { virtuales: un estudio de } \\
\text { caso en la formación de } \\
\text { profesores de física }\end{array}$ & $\begin{array}{l}\text { Hernández, C. y } \\
\text { Tecpan, S. }\end{array}$ & Chile & Español \\
\hline $\begin{array}{l}\text { Google } \\
\text { Scholar }\end{array}$ & $\begin{array}{l}\text { Plataforma } \\
\text { virtual }\end{array}$ & $\begin{array}{l}\text { 2018-Revista } \\
\text { Atlante: } \\
\text { Cuadernos de } \\
\text { Educación y } \\
\text { Desarrollo }\end{array}$ & Articulo & $\begin{array}{l}\text { La importancia del uso } \\
\text { de las plataformas } \\
\text { virtuales en la educación } \\
\text { superior. }\end{array}$ & $\begin{array}{l}\text { Barrera, V. y Guapi, } \\
\text { A. }\end{array}$ & España & Español \\
\hline Scielo & Aprendizaje & $\begin{array}{l}\text { 2016-Revista } \\
\text { Universidad y } \\
\text { Sociedad }\end{array}$ & Articulo & $\begin{array}{l}\text { Diseño e } \\
\text { implementación de un } \\
\text { Entorno Virtual de } \\
\text { Aprendizaje (EVA) } \\
\text { utilizando la plataforma } \\
\text { educativa Moodle. } \\
\text { Estudio de caso: } \\
\text { asignatura Ergonomía. } \\
\text { Universidad de } \\
\text { Cienfuegos, Cuba }\end{array}$ & $\begin{array}{l}\text { Barrera, A., Peña, I. } \\
\text { y Peña, M. }\end{array}$ & Cuba & Español \\
\hline
\end{tabular}




\begin{tabular}{|c|c|c|c|c|c|c|c|}
\hline $\begin{array}{l}\text { Blackboard } \\
\text { Inc. }\end{array}$ & $\begin{array}{l}\text { Plataforma } \\
\text { virtual }\end{array}$ & $\begin{array}{l}2020- \\
\text { Blackboard } \\
\text { Inc. }\end{array}$ & Articulo & $\begin{array}{l}\text { Blackboard Collaborate } \\
\text { Online Collaboration } \\
\text { Tools That Engage } \\
\text { Everyone, Every Time, } \\
\text { Everywhere. }\end{array}$ & $\begin{array}{l}\text { [Plataforma } \\
\text { Blackboard] }\end{array}$ & EE.UU. & English \\
\hline $\begin{array}{l}\text { Google } \\
\text { Scholar }\end{array}$ & Virtual platform & $\begin{array}{l}2019- \\
\text { Innovación } \\
\text { Educativa, }\end{array}$ & Articulo & $\begin{array}{l}\text { MITS: sistema de tutoría } \\
\text { inteligente para asistir al } \\
\text { profesorado en el uso de } \\
\text { MOODLE. }\end{array}$ & $\begin{array}{l}\text { Campos, M.A. y } \\
\text { Menéndez, V.H y } \\
\text { Zapata, A. }\end{array}$ & México & Español \\
\hline Dialnet & $\begin{array}{l}\text { Plataforma } \\
\text { virtual }\end{array}$ & $\begin{array}{l}\text { 2019-REDU: } \\
\text { Revista de } \\
\text { Docencia } \\
\text { Universitaria }\end{array}$ & Articulo & $\begin{array}{l}\text { Los usos de las } \\
\text { plataformas digitales en } \\
\text { la enseñanza } \\
\text { universitaria. } \\
\text { Perspectivas desde la } \\
\text { investigación educativa }\end{array}$ & $\begin{array}{l}\text { De Pablos, J., Bravo, } \\
\text { C., López A. y } \\
\text { Lázaro, I. }\end{array}$ & España & Español \\
\hline Recimundo & Virtual platform & $\begin{array}{l}2020- \\
\text { Recimundo }\end{array}$ & Articulo & $\begin{array}{l}\text { Las plataformas virtuales } \\
\text { para fomentar } \\
\text { aprendizaje colaborativo } \\
\text { en los estudiantes del } \\
\text { bachillerato. }\end{array}$ & $\begin{array}{l}\text { De la cruz, T., } \\
\text { Macías, G. y Chisag, } \\
\text { C. }\end{array}$ & España & Español \\
\hline $\begin{array}{l}\text { Google } \\
\text { Scholar }\end{array}$ & Aprendizaje & $\begin{array}{l}\text { 2019-Revista } \\
\text { Electrónica } \\
\text { Interuniversit } \\
\text { aria de } \\
\text { Formación } \\
\text { del } \\
\text { Profesorado }\end{array}$ & Articulo & $\begin{array}{l}\text { Huellas de los } \\
\text { estudiantes en las } \\
\text { plataformas virtuales. } \\
\text { Aplicación para evaluar } \\
\text { una metodología de } \\
\text { aprendizaje activo }\end{array}$ & De la Iglesia, M. & España & Español \\
\hline $\begin{array}{l}\text { Revistas } \\
\text { interconecta } \\
\text { ndo saberes }\end{array}$ & $\begin{array}{l}\text { Plataforma } \\
\text { virtual }\end{array}$ & $\begin{array}{l}\text { 2017-Revistas } \\
\text { interconectan } \\
\text { do saberes }\end{array}$ & Articulo & $\begin{array}{l}\text { Plataformas Virtuales de } \\
\text { Aprendizaje en la } \\
\text { Educación Superior. }\end{array}$ & Escobar, A. & Mexico & Español \\
\hline $\begin{array}{l}\text { Google } \\
\text { Scholar }\end{array}$ & $\begin{array}{l}\text { Educación a } \\
\text { distancia }\end{array}$ & $\begin{array}{l}2020- \\
\text { Iberoamerican } \\
\text { a de } \\
\text { Educación a } \\
\text { Distancia }\end{array}$ & Articulo & $\begin{array}{l}\text { Bosque semántico: } \\
\text { ¿educación/enseñanza/ap } \\
\text { rendizaje a distancia, } \\
\text { virtual, en línea, digital, } \\
\text { eLearning...? }\end{array}$ & García, L. & España & Español \\
\hline Scielo & $\begin{array}{l}\text { Aprendizaje } \\
\text { virtual }\end{array}$ & 2017-Sophia & Articulo & $\begin{array}{l}\text { Aplicación de las TIC en } \\
\text { modelos educativos } \\
\text { blended learning: Una } \\
\text { revisión sistemática de } \\
\text { literatura }\end{array}$ & $\begin{array}{l}\text { Gonzales, A., } \\
\text { Perdomo, V. y } \\
\text { Smith, Y. }\end{array}$ & Colombia & Español \\
\hline Scielo & $\begin{array}{l}\text { Aprendizaje } \\
\text { colaborativo }\end{array}$ & $\begin{array}{l}\text { 2017- } \\
\text { Estudios } \\
\text { pedagógicos }\end{array}$ & Articulo & $\begin{array}{l}\text { Aula invertida mediada } \\
\text { por el uso de plataformas } \\
\text { virtuales: un estudio de } \\
\text { caso en la formación de } \\
\text { profesores de física. }\end{array}$ & $\begin{array}{l}\text { Hernández C. y } \\
\text { Tecpan S. }\end{array}$ & Chile & Español \\
\hline Scielo & $\begin{array}{l}\text { Educación a } \\
\text { distancia }\end{array}$ & $\begin{array}{l}2020- \\
\text { Enfermería } \\
\text { global }\end{array}$ & Articulo & $\begin{array}{l}\text { Módulo educativo en } \\
\text { ambiente virtual de } \\
\text { aprendizaje en Diabetes } \\
\text { Mellitus. Enfermería } \\
\text { Global, }\end{array}$ & $\begin{array}{l}\text { Lima de Castillo, } \\
\text { W., Ribeiro, S.R., } \\
\text { Barduchi, R., Antar, } \\
\text { m. y De Oliveira, } \\
\text { M.A. }\end{array}$ & Brasil & Español \\
\hline $\begin{array}{l}\text { Google } \\
\text { Scholar }\end{array}$ & $\begin{array}{l}\text { Educación } \\
\text { virtual }\end{array}$ & 2018-Scielo & Articulo & $\begin{array}{l}\text { Inadaptability of teachers } \\
\text { to the management of } \\
\text { virtual platforms }\end{array}$ & $\begin{array}{l}\text { Mora, E., Bonilla, J., } \\
\text { Núñez, L. y } \\
\text { Sarmiento J. }\end{array}$ & Ecuador & English \\
\hline $\begin{array}{l}\text { Google } \\
\text { Scholar }\end{array}$ & Aprendizaje & $\begin{array}{l}\text { 2019-Revista } \\
\text { Electrónica } \\
\text { Formación y } \\
\text { Calidad } \\
\text { Educativa. }\end{array}$ & Articulo & $\begin{array}{l}\text { Consideraciones para el } \\
\text { diseño del proceso de } \\
\text { enseñanza-aprendizaje } \\
\text { de la asignatura Sistici, } \\
\text { con el uso de las } \\
\text { tecnologías de la } \\
\text { información y las } \\
\text { comunicaciones }\end{array}$ & $\begin{array}{l}\text { Mulet, T. y Flores, } \\
\text { F. }\end{array}$ & Ecuador & Spanish \\
\hline $\begin{array}{l}\text { Science } \\
\text { Direct }\end{array}$ & Learning & 2018-Elsevier & Articulo & $\begin{array}{l}\text { Designating criteria for } \\
\text { educational technology } \\
\text { assessmen }\end{array}$ & $\begin{array}{l}\text { Noriega, I., Eraña I., } \\
\text { Segura, N., Fuentes, } \\
\text { A. y López, M. }\end{array}$ & México & English \\
\hline
\end{tabular}




\begin{tabular}{|c|c|c|c|c|c|c|c|}
\hline $\begin{array}{l}\text { Google } \\
\text { Scholar }\end{array}$ & $\begin{array}{l}\text { Plataforma } \\
\text { Virtual }\end{array}$ & $\begin{array}{l}2019- \\
\text { Repositorio } \\
\text { Universidad } \\
\text { Politécnica de } \\
\text { Sinaloa }\end{array}$ & Tesis & $\begin{array}{l}\text { El Uso de Plataformas } \\
\text { Virtuales para el } \\
\text { Aprendizaje }\end{array}$ & Lora, J.M. & México & Español \\
\hline $\begin{array}{l}\text { Google } \\
\text { Scholar }\end{array}$ & Aprendizaje & $\begin{array}{l}\text { 2017-Innova } \\
\text { Research } \\
\text { Journal }\end{array}$ & Articulo & $\begin{array}{l}\text { Uso de las tecnologías de } \\
\text { la información en la } \\
\text { educación superior }\end{array}$ & $\begin{array}{l}\text { Remache, P. y } \\
\text { Moreno, A. }\end{array}$ & España & Español \\
\hline $\begin{array}{l}\text { Revista } \\
\text { Complutens } \\
\text { e de } \\
\text { Educación, }\end{array}$ & Learning & $\begin{array}{l}\text { 2018-Revista } \\
\text { Complutense } \\
\text { de Educación, }\end{array}$ & Articulo & $\begin{array}{l}\text { El empoderamiento del } \\
\text { alumnado en los } \\
\text { sMOOC/[en] The } \\
\text { students empowerment } \\
\text { in the sMOOC }\end{array}$ & $\begin{array}{l}\text { Quintana, G. y } \\
\text { Pérez, M. }\end{array}$ & España & Español \\
\hline $\begin{array}{l}\text { Repostiorio } \\
\text { de la } \\
\text { Universidad } \\
\text { Nacional } \\
\text { del Centro } \\
\text { del Perú }\end{array}$ & $\begin{array}{l}\text { Plataforma } \\
\text { virtual }\end{array}$ & $\begin{array}{l}\text { 2019- } \\
\text { Repostiorio } \\
\text { de la } \\
\text { Universidad } \\
\text { Nacional del } \\
\text { Centro del } \\
\text { Perú }\end{array}$ & Tesis & $\begin{array}{l}\text { Aplicación de la } \\
\text { plataforma virtual LMS } \\
\text { para mejorar el programa } \\
\text { de capacitación laboral } \\
\text { en el Colegio Particular } \\
\text { Andino-Huancayo } 2019 \text {. }\end{array}$ & Santivañez, S. & Perú & Español \\
\hline $\begin{array}{l}\text { Revista } \\
\text { Electrónica } \\
\text { Sobre } \\
\text { Tecnología, } \\
\text { Educación } \\
\text { Y Sociedad }\end{array}$ & Plataforma & $\begin{array}{l}\text { 2019-Revista } \\
\text { Electrónica } \\
\text { Sobre } \\
\text { Tecnología, } \\
\text { Educación Y } \\
\text { Sociedad }\end{array}$ & Articulo & $\begin{array}{l}\text { Plataforma virtual para } \\
\text { reforzar el proceso de } \\
\text { acreditación en las } \\
\text { Facultades del Área de } \\
\text { Humanidades }\end{array}$ & $\begin{array}{l}\text { Terán, L., Arano, E., } \\
\text { Maldonado, U. y } \\
\text { González, J. }\end{array}$ & Mexico & Español \\
\hline $\begin{array}{l}\text { European } \\
\text { Scientific } \\
\text { Journal }\end{array}$ & $\begin{array}{l}\text { Plataforma } \\
\text { Virtual }\end{array}$ & $\begin{array}{l}2019- \\
\text { European } \\
\text { Scientific } \\
\text { Journal }\end{array}$ & Articulo & $\begin{array}{l}\text { Uso De Plataformas } \\
\text { Virtuales De } \\
\text { Aprendizaje En El } \\
\text { Desarrollo Cognitivo De } \\
\text { Estudiantes De Nivel } \\
\text { Superior. }\end{array}$ & $\begin{array}{l}\text { Tixi, D., Quinde, C., } \\
\text { Chunata, I. y Niama, } \\
\text { C. }\end{array}$ & Ecuador & Español \\
\hline \multirow[t]{2}{*}{$\begin{array}{l}\text { Revista } \\
\text { Electrónica } \\
\text { Educare }\end{array}$} & $\begin{array}{l}\text { Plataforma } \\
\text { virtual }\end{array}$ & $\begin{array}{l}\text { 2018-Revista } \\
\text { Electrónica } \\
\text { Educare }\end{array}$ & Articulo & $\begin{array}{l}\text { El uso de plataformas } \\
\text { virtuales y su impacto en } \\
\text { el proceso de aprendizaje } \\
\text { en las asignaturas de las } \\
\text { carreras de Criminología } \\
\text { y Ciencias Policiales, de } \\
\text { la Universidad Estatal a } \\
\text { Distancia de Costa Rica }\end{array}$ & $\begin{array}{l}\text { Vargas, A. y } \\
\text { Villalobos, G. }\end{array}$ & Costa Rica & Español \\
\hline & Aprendizaje & $\begin{array}{l}\text { 2018-@tic. } \\
\text { revista } \\
\text { d'innovación } \\
\text { educativa }\end{array}$ & Articulo & $\begin{array}{l}\text { Aprendizaje cooperativo } \\
\text { a través de las nuevas } \\
\text { tecnologías }\end{array}$ & $\begin{array}{l}\text { Valverde, H. y } \\
\text { Baños, R. }\end{array}$ & España & Español \\
\hline
\end{tabular}

Fuente. Elaboración propia (2021). 


\section{La plataforma Blackboard}

Con la llegada de la globalización a mediados de los años noventa, surgen las plataformas que permiten la gestión de cursos en los que no son necesario el conocimiento profundo. Blackboard fue fundada en 1997 por Michael Chasen, Matthew Pittinsky, Stephen Gilfus and Daniel Cane. Surgió como firma consultora y un contrato con MS Global Learning Consortium, organización sin fines de lucro. Actualmente, la mayoría de plataformas son programas computacionales (software) o equipos electrónicos (hardware).

Blackboard Learning System ${ }^{\text {Tx }}$ es una plataforma computacional, flexible, sencilla e intuitiva utilizada en muchas universidades del planeta; contiene funciones básicas para la creación de contenidos y documentos necesarios para la administración mediante internet de un curso semipresencial o a distancia. Ésta, permite optimizar el desempeño individual, beneficia la eficacia de la enseñanza y el aprendizaje; permite tomar decisiones, mejorar los resultados; ofrece la interacción y la experiencia de un aprendizaje individualizado. Integra herramientas; actividades para administrar, intercambiar y registrar la formación académica a través de internet (De Pablos et al., 2019). Permite que los estudiantes puedan seguir de acuerdo a los diferentes ritmos de aprendizaje que poseen, pues ayuda a que construyan sus saberes contando con el apoyo y monitoreo de un docente que emplea una variedad de estrategias didácticas en combinación con las herramientas o recursos que ofrece la plataforma. Por supuesto que eso no es todo, también se desarrolla pensamiento crítico, creativo y colaborativo, procesos que dependerán de la creatividad, innovación y dominio pedagógico del docente a cargo de un grupo de estudiantes (Barrera y Guapi, 2018). Confluyen, por tanto, un aprendizaje individualizado y otro colaborativo que obliga al estudiante a involucrarse en las actividades propuestas, su evaluación y coevaluación.

Las instituciones educativas de nivel superior y también básica enfrentan grandes desafíos vinculados a la innovación tecnológica al servicio de la formación profesional. Como explican Gil y
Martínez (2018, p.59): “los desafíos más importantes a los que se enfrentan las instituciones universitarias, por la proyección de los espacios de formación MOOC, derivan de las innovaciones disruptivas que éstos llevan consigo, otorgando un protagonismo vital al alumnado". Es importante la actitud favorable y proactiva del estudiante frente a una educación a distancia; pero también la preparación y óptimo desempeño del docente como garantía para una enseñanza de calidad, con aprendizajes que trasciendan lo síncrono o asíncrono.

El docente innovador, que asume retos y apuesta por explorar nuevas posibilidades de enseñanza y aprendizaje, se desempeñará mejor en este tipo de educación que cuando estaba en un aula física en la modalidad presencial. Al respecto, Campos, Menéndez y Zapata (2019, p. 35) señalan que:

Las características de mayor relevancia son la facilidad de uso del sistema y que los usuarios consideraron que puede resultar en una herramienta útil, tanto para la formación de profesores como para la interacción con sus cursos y tareas dentro del entorno de MOODLE.

Pese a ello, hay que lamentar que todavía no se aprovecha la plataforma Blackboard en su real dimensión ni se exploran las posibilidades que ofrece como herramienta innovadora y transformadora, sino que tanto docentes como estudiantes prefieran un modelo tradicional de enseñanza y aprendizaje presencial (Villalón, Luna y García, 2019).

\section{Principales características de la plataforma Blackboard}

La plataforma Blackboard permite a los usuarios personalizar el perfil, con el cual se vinculan directamente a los cursos, acceder a las retroalimentaciones, mensajes, calendarizaciones y resultados. Gracias a esto adquiere autonomía, ya que puede realizar reajustes (Mulet y Flores 2019). Los usuarios podrán ver toda la información relevante completa, las actividades de aprendizaje y también comunicarse con otros. Desde su portal individual, cada usuario verá las noticias del sitio 
y demás documentación disponible.

Se debe destacar las consideraciones previas que los usuarios deben conocer, siendo uno de los grandes beneficios de esta plataforma es que cuenta con su propia nube, por ende, el usuario puede acceder a su contenido. Para emplear esta plataforma, no se necesita ningún software o hardware. Se accede a ella mediante un explorador de web, con cookies activadas y conectadas. Soporta a los principales exploradores, como Firefox, Internet Explorer, Safari, Google Chrome, Edge, Opera (Help Blackboard, 2021).

Además, la facilidad de uso de Blackboard se presenta como una herramienta versátil que ofrece una experiencia de aprendizaje moderna, en la que los estudiantes pueden desarrollar aprendizajes en forma individual o colaborativa, a continuación, se describe las principales características de la plataforma.

Para la ejecución y desarrollo, la plataforma Blackboard ofrece herramientas de desarrollo de cursos simples, pero altamente avanzadas. Se puede crear plantillas de cursos para que los docentes/ tutores puedan organizar sus cursos. Estos pueden arrastrar y soltar directamente en su curso cualquier tipo de archivo, incluyendo audio y vídeo, paquetes Shareable Content Object Reference Model (SCORM), documentos de Microsoft Office, y otros. También es posible agregar texto y elementos interactivos como: paneles de discusión, wikis, blogs, encuestas, evaluaciones y otros. Con esta funcionalidad, los tutores y administradores pueden cargar contenido y crear elementos interactivos. A medida que renueva o actualiza la información, se modifica el acceso dependiendo del grupo y la interacción con este. El entorno comunicativo que ofrece Blackboard vence cualquier obstáculo relacionado con el espacio y el tiempo y permite que los estudiantes interactúen en las clases en línea gestionadas por los docentes (Almenar et al., 2019).

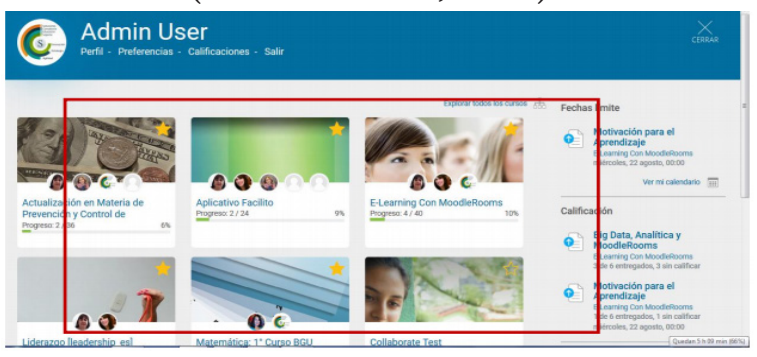

Figura 2. Página de perfil de Blackboard (2021). Fuente. Plataforma Blackboard.
Aún sin ingresar a un curso en particular, cada usuario puede revisar información relacionada con la fecha límite de entrega de tareas o la realización de actividades en cualquiera de los cursos en que está matriculado, la calificación obtenida, mensajes recibidos y mensajes de foro a revisar. Todo esto se encuentra a la derecha de donde se muestran los cursos (Blackboard Inc, 2020).

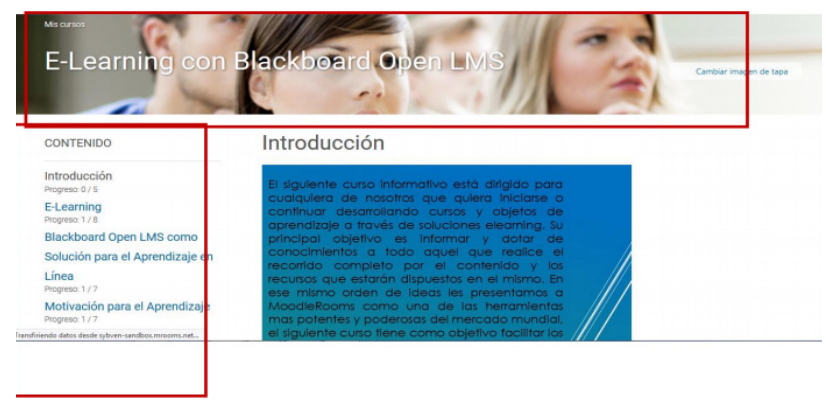

Figura 3. Página principal del curso en la plataforma Blackboard (2021).

Fuente. Plataforma Blackboard.

Al ingresar a cada uno de esos contenidos, el docente diseña y rellena dicho espacio con información que es colocada en los diferentes recursos y espacios que ofrece la plataforma. En la figura 4 se muestra cómo se visualiza una primera unidad o tema, la cual contiene información o contenido en formato de vídeo, en formato SCORM, contenido colocado en un recurso llamado "Libro", un espacio de "Chat" para reunirse el docente y sus alumnos, un espacio de integración con la herramienta externa "Blackboard Collaborate" en la que se puede realizar una videoconferencia entre docente y estudiantes (Blackboard Inc, 2020).

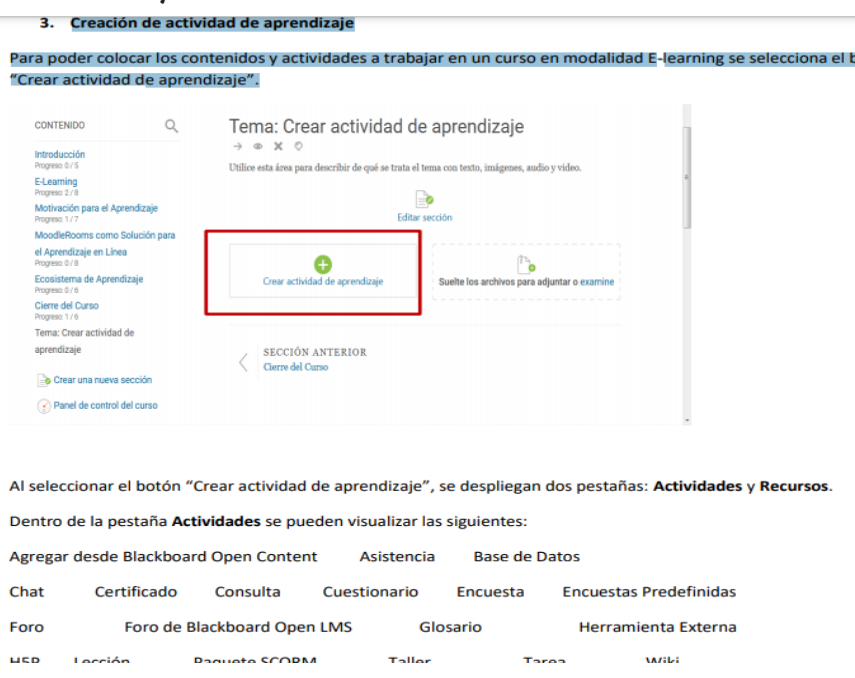

Figura 4. Icono para crear una nueva unidad o tema en la plataforma Blackboard (2021).

Fuente. Plataforma Blackboard. 
Otro de los recursos que posee la plataforma Blackboard es la creación de una nueva sección, si se requiere agregar una nueva sección, ya sea una nueva unidad o tema, se hace seleccionando el botón "Creación de una nueva sección" (figura $5)$.

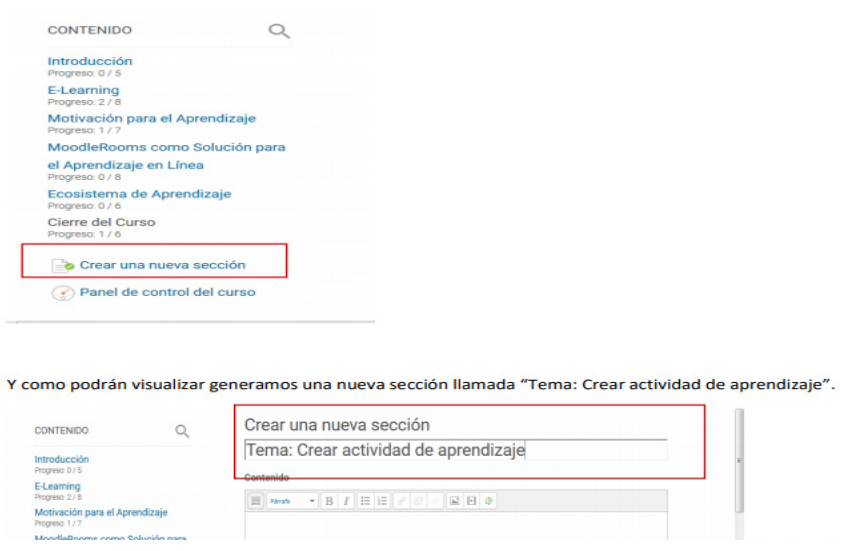

Figura 5. Icono para crear una nueva sección en la plataforma Blackboard (2021). Fuente. Plataforma Blackboard.

La Creación de actividades de aprendizaje, permite colocar los contenidos y actividades a desarrollar en un curso en modalidad E-learning. Para ello se selecciona el botón: "Crear actividad de aprendizaje". Adicionalmente, se pueden integrar otras herramientas, como Blackboard Collaborate (herramienta síncrona - videoconferencia) y algunos recursos externos.

La plataforma Blackboard permite realizar una serie de actividades y funciones, las cuales se describen en la tabla 2.

Tabla 2. Principales actividades y funciones de la plataforma Blackboard.

\begin{tabular}{cl}
\hline Actividades & \multicolumn{1}{c}{ Funciones } \\
\hline Asistencia & Permite tomar asistencia en clase o que el \\
& estudiante la marque. \\
\hline Base de datos & Los participantes pueden buscar \\
& información dentro de un repositorio de \\
& registro, a su vez las evaluaciones se \\
& registran en el libro de calificaciones. \\
\hline Chat & Permite a los estudiantes compartir \\
& experiencias con otros compañeros del \\
& mismo curso, de diferentes ciudades o \\
& países, a su vez se puede repetir por hora, \\
& día o semana.
\end{tabular}

\begin{tabular}{|c|c|}
\hline Consulta & $\begin{array}{l}\text { Ofrece la posibilidad de realizar preguntas } \\
\text { con probables respuestas que son } \\
\text { publicadas después de que se haya } \\
\text { respondido al cuestionario en la fecha } \\
\text { indicada, considerando el anonimato. }\end{array}$ \\
\hline Cuestionario & $\begin{array}{l}\text { Presenta varias opciones: opción múltiple, } \\
\text { verdadero/falso, preguntas tipo ensayo, } \\
\text { respuestas cortas, entre otras. Además, } \\
\text { brinda la opción de retroalimentar a cada } \\
\text { pregunta. }\end{array}$ \\
\hline Encuesta & $\begin{array}{l}\text { Esta actividad permite diseñar diversas } \\
\text { preguntas que le será útil para recopilar } \\
\text { información. }\end{array}$ \\
\hline Foro & $\begin{array}{l}\text { Presenta diferentes opciones como, por } \\
\text { ejemplo: debates, respuestas, avisos de } \\
\text { curso y generación de espacios de } \\
\text { intercambios sociales. }\end{array}$ \\
\hline Glosario & $\begin{array}{l}\text { Permite a los estudiantes crear listas de } \\
\text { definiciones, como un diccionario. }\end{array}$ \\
\hline Lección & $\begin{array}{l}\text { Tiene la opción de crear contenidos y } \\
\text { actividades de repaso del curso. }\end{array}$ \\
\hline Paquetes Scorm & $\begin{array}{l}\text { Cargar o añadir documentos o archivos en } \\
\text { un solo paquete. }\end{array}$ \\
\hline Taller & Enviar cualquier contenido digital. \\
\hline Tarea & $\begin{array}{l}\text { Permite evaluar el aprendizaje mediante } \\
\text { las consignas que realiza el docente. Tiene } \\
\text { la opción de presentarse como archivos, } \\
\text { audio, video, PPT, PDF, entre otras. }\end{array}$ \\
\hline Wiki & $\begin{array}{l}\text { Permite editar colecciones de páginas web, } \\
\text { en forma colaborativa o individual. }\end{array}$ \\
\hline H5P & $\begin{array}{l}\text { Es completo, pues permite crear } \\
\text { contenidos interactivos, preguntas de } \\
\text { arrastrar y soltar, entre otras opciones. }\end{array}$ \\
\hline $\begin{array}{l}\text { Herramienta } \\
\text { Externa }\end{array}$ & $\begin{array}{l}\text { Integra la clase síncrona, como es la } \\
\text { videoconferencia. }\end{array}$ \\
\hline
\end{tabular}

Fuente. Elaboración propia (2021).

Dentro de la pestaña Recursos se pueden visualizar las siguientes: archivo, carpeta, etiqueta, libro, página, paquete de contenido IMS, URL. 


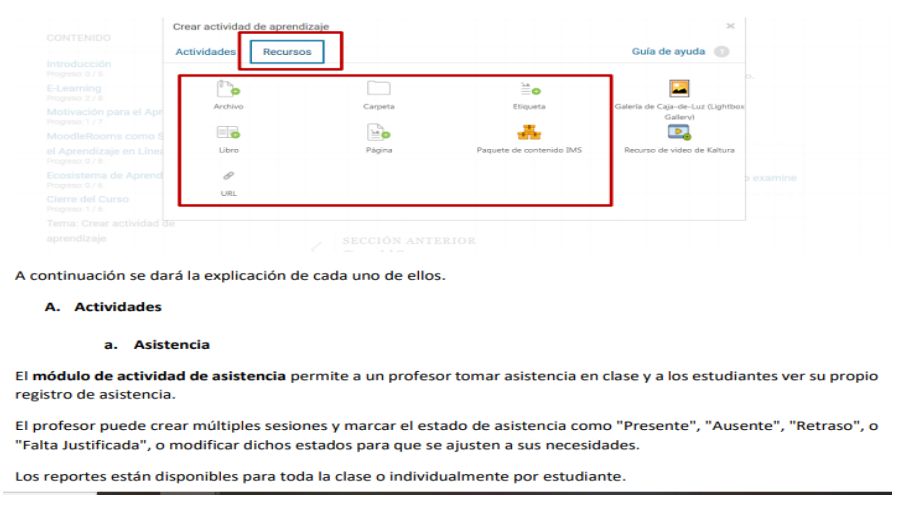

Recursos. En la tabla 3 se detalla las funciones de cada recurso.

Tabla 3. Principales recursos y funciones de la plataforma Blackboard

\begin{tabular}{cc}
\hline Recursos & Funciones \\
\hline Archivo & $\begin{array}{c}\text { Permite compartir diferentes tipos de } \\
\text { archivos como PDF, Word, Excel, PPT, } \\
\text { imágenes, entre otras. }\end{array}$ \\
Carpeta & $\begin{array}{c}\text { Muestra todos los archivos dentro de una } \\
\text { carpeta y permite subir un archivo } \\
\text { comprimido (zip). }\end{array}$ \\
Página & $\begin{array}{c}\text { Permite crear página web mediante su } \\
\text { editor de texto y puede mostrar otros } \\
\text { Libro }\end{array}$ \\
& $\begin{array}{c}\text { Permite crear formato en capítulo y } \\
\text { subcapítulos, e inclusive se puede incluir } \\
\text { multimedia. }\end{array}$ \\
& $\begin{array}{c}\text { Ayuda a mejorar la apariencia de un curso. } \\
\text { Proporciona enlaces de internet que están } \\
\text { URL }\end{array}$ \\
& en línea como documentos, imágenes, \\
& audio, entre otras.
\end{tabular}

Fuente. Elaboración propia (2021).

Panel de control del curso. Área desde la cual se monitorea el curso y se administran todas las actividades. En la figura 7 se muestra el icono de acceso.

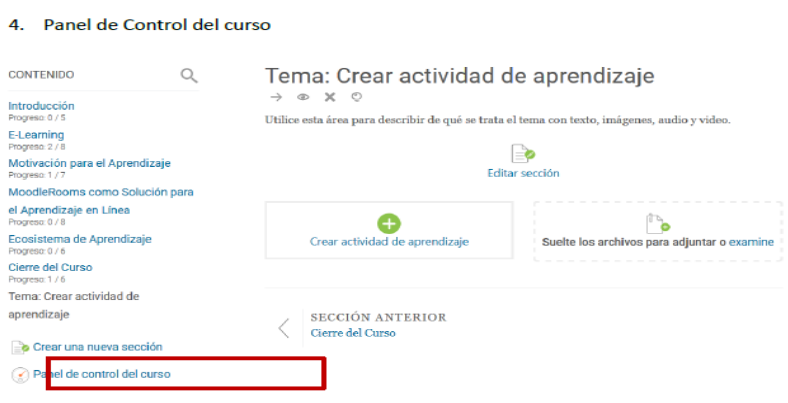

Figura 7. Icono para acceder a panel de control del curso plataforma Blackboard (2021).

Fuente. Plataforma Blackboard.

En el Panel de Control del curso el docente encontrará: ajuste del curso, calificador de Blackboard, open LMS, libro de calificaciones, participantes del curso, informes de Blackboard, PLD (Diseñador de Aprendizaje Personalizado), competencias, resultados, insignias.

Calificador de Blackboard Open LMS. Open LMS "permite a los profesores docentes personalizar rutas de aprendizaje en línea y presentar contenido dinámico que se adapte a las necesidades de cada estudiante" (Help Blackboard, 2021, párr. 1). En el caso del calificador de Blackboard, este brinda la opción de revisar las entregas de los estudiantes y calificarlas. Durante ese proceso, el docente se desplaza por ellas, en una vista simplificada y ajustable de dos paneles. Actualmente, se admiten solo las actividades y los foros de Blackboard en el calificador. Se pueden hacer correcciones y comentarios sobre los archivos en formato PDF dentro del calificador; usar flujos de trabajo de calificación y delegar la calificación. Los docentes y los estudiantes pueden debatir sobre una entrega o una calificación en particular en los comentarios de la actividad. Asimismo, pueden ver solo sus propias entregas y calificaciones en el calificador.

A su vez, es necesario implementar encuestas a los estudiantes para realizar una retroalimentación y calificar, proceso que se realiza mediante la plataforma virtual (Barrera, Peña y Peña, 2016). Es decir, la plataforma no solo sirve para calificar al estudiante, también los docentes son evaluados por parte del estudiante. Se permite la coevaluación para un mejor desarrollo del proceso de enseñanza-aprendizaje. Lo importante es que 
la plataforma permite realizar diferentes actividades, como: actualizar el material, interacción entre estudiantes, favoreciéndose así la construcción del aprendizaje de forma permanente y reflexiva (Vargas y Villalobos, 2018).

Hablar de educación a distancia implica, por un lado, elegir una plataforma que ofrezca herramientas y funcionalidades que faciliten los procesos didácticos, el diseño curricular, el desarrollo de competencias y otras actividades conexas, y por otro, que el usuario sea el principal protagonista de su aprendizaje. Por esta razón, se deben conocer y evaluar las ventajas y desventajas de dicha plataforma antes de contratar con el proveedor del servicio. Blackboard, como otras plataformas diseñadas para el aprendizaje, además de facilitar el aprendizaje colaborativo, ofrecen la posibilidad de potenciar "algunas habilidades cognitivas que dependen directamente del estímulo específico de cada una de estas" (Viñas, 2017, p. 168). Esto se da gracias a la creatividad desplegada por los estudiantes en el proceso de comunicación interactiva y la publicación de información relacionada con los intereses de aprendizaje.

\section{Finalidad de la plataforma Blackboard}

Esta plataforma como herramienta y espacio para la enseñanza-aprendizaje es utilizada por instituciones de nivel educativo básico y universitario, ha sido diseñada pensando en que los estudiantes la vean semejante a otras herramientas que utilizan en su vida diaria (Cornejo et al., 2020). La facilidad de accesibilidad, al requerir que solamente se tenga señal de internet y que los usuarios seleccionen su horario para acceder a las actividades facilita su interacción con los usuarios. Asimismo, la plataforma permite que docentes y estudiantes interactúen en forma asincrónica, sin necesidad de estar en un aula física y con la interesante y entretenida posibilidad de realizar actividades a distancia (González, Perdomo y Smith, 2017).

Como nueva experiencia para una institución que incursiona bajo esta nueva modalidad de aprendizaje, es natural que traiga consigo un re- chazo inicial y que el proceso de adaptación de docentes y estudiantes sea lento. Unos y otros tienen necesidades frente a la implementación de Blackboard; pero se mira todo desde la óptica de los estudiantes, y se puede afirmar que se debe mejorar el acceso a internet y a la plataforma misma; que se preparen materiales de aprendizaje suficientes, pertinentes y necesarios y que se capacite a docentes y estudiantes en el manejo de la herramienta (Aguilar, De las Fuentes y Rivera, 2019).

Cabe destacar que la plataforma virtual es una necesidad, sobre todo en estos tiempos en el que la educación se ha virtualizado. En la que las actividades requieren un seguimiento y evaluación de los aprendizajes y necesitan estar alineados a la programación curricular. Para que el modelo funcione, son necesarios la supervisión y acompañamiento del docente en todo el proceso (Tixi, Chunata \& Niama, 2019). La elección e implementación de la plataforma virtual dependerá de muchos factores, que pueden ir desde la política institucional hasta el requerimiento de los cursos (Escobar, 2017). Las instituciones educativas interesadas en revolucionar el servicio que brindan evaluarán las ventajas y desventajas de cada plataforma disponible antes de decidirse por aquella que cambiará la visión actual del proceso de enseñanza-aprendizaje y la vida de sus docentes y estudiantes.

\section{Ventajas de las plataformas virtuales}

Entre las principales ventajas de Blackboard se puede mencionar: (i) permite un contacto sincrónico y bidireccional con los estudiantes; (ii) facilita distintas actividades (clase magistral, videoconferencias, etc.) y la grabación de la clase o videoconferencia; (iii) permite enriquecer los contenidos de la asignatura; (iv) facilita la retroalimentación inmediata a cada concepto o trabajo; (v) tiene la opción de compartir archivos, videos, páginas web, audios, carpetas, Uniform Resource Locator (URL), entre otros; (vi) facilita diseñar encuestas, pruebas y exámenes y (vii) permite realizar seguimiento del desempeño de los estudiantes (Villalón y García, 2019). 
El estudiante aprende gracias a los contenidos atractivos y de fácil comprensión. Mediante esta plataforma se puede conocer rápidamente las calificaciones de una autoevaluación, programando formularios o exámenes de calificación automática, cuyos contenidos se pueden actualizar (Santivañez, 2019). La plataforma permite al estudiante conocer de manera inmediata sus calificaciones, algo que no es usual en la modalidad presencial. Por consiguiente, Blackboard debe ser parte del trabajo pedagógico; el docente tiene el reto de rediseñar, restructurar y actualizar su contenido para garantizar que se cumpla con los objetivos y acompañe a los estudiantes en el desarrollo de sus competencias; pero también es indispensable que estos últimos se comprometan en el proceso (Remache, Puente y Moreno, 2017). De nada sirve que el docente invierta tiempo y esfuerzo en la configuración de un aula virtual atractiva, con materiales de calidad y actividades retadoras, si el estudiante muestra apatía y desinterés. Cualquier iniciativa pedagógica innovadora fracasará si aquellos a quienes va dirigida no hacen el menor esfuerzo ni muestran interés por aprender. La incursión en una plataforma virtual favorece enormemente el proceso de enseñanza-aprendizaje; los docentes encuentran motivación para la innovación metodológica y los estudiantes mejoran sus desempeños y desarrollan las competencias previstas (Herrada y Baños, 2018). La TIC, en cualquiera de sus modalidades, permiten que los docentes innoven su práctica pedagógica, desarrollen materiales educativos variados, con distintos formatos y secuencias (Lima et al., 2020, p. 356). Con el aprovechamiento de estos recursos, las actividades de aprendizaje se tornan motivadoras y se apoyan en materiales educativos retadores, interesantes, atractivos, dinámicos y accesibles que facilitan el aprendizaje de los estudiantes.

Desventajas de las plataformas virtuales Así como Blackboard es una plataforma adecuada $y$, bien utilizada, puede ser un estupendo aliado para docentes y estudiantes. Como cualquier otra plataforma virtual, también tiene sus desventajas. Morales et al., (2020), señalan cinco desventajas de las plataformas virtuales, en gene- ral. Estas son aplicables también para la plataforma Blackboard:

a) mayor tiempo y dedicación por parte del profesor,

b) necesidad de que el estudiante [disponga] permanentemente de los medios informáticos [indispensables],

c) no todos los docentes cuentan con conocimientos básicos de informática necesarios,

d) [necesidad de] mayor esfuerzo y disciplina que en las clases presenciales,

e) [ausencia de] contacto directo. (pp. 16-17)

La necesidad de mayor tiempo y dedicación por parte del docente. En la educación virtual, la preparación de los materiales, el monitoreo de las actividades y el apoyo a los estudiantes demanda más tiempo al docente. Este termina agotado, con síntomas de estrés que pueden afectar seriamente su salud.

La disponibilidad permanente de medios informáticos en los estudiantes. Este es un tema complejo; no todos los estudiantes disponen de recursos suficientes para adquirir las herramientas tecnológicas requeridas para una conexión exitosa a la plataforma y realizar sin dificultad las actividades.

Deficientes conocimientos básicos de informática en los docentes. Esto se evidencia cuando deben aplicar nuevas tecnologías, tienen dificultades para hacerlo y, como consecuencia de ello, experimentan frustración. Es algo inevitable contra lo que los docentes deben prepararse, pues los avances de la tecnología no se detienen. Cada día las invenciones sorprenden tratando de hacer más sencilla la vida del hombre. Si se cuenta con recursos para acceder a los nuevos productos tecnológico, se puede aprovechar los beneficios de aquello para lo cual estos fueron creados. Precisamente, toda plataforma virtual está en permanente proceso de mejora para ser más funcional y accesible, vincularse a nuevas herramientas externas y optimizar el servicio que ofrecen.

Inversión de esfuerzo y disciplina en los estudian- 
tes. Estos suelen desarrollar con frecuencia deficientes hábitos de estudio que afectan su proceso de aprendizaje. Pasan demasiado tiempo solos, navegando en las redes sociales, en actividades no académicas diversas o realizando vida social. Como resultado de ello, postergan el desarrollo y entrega oportuna de sus actividades académicas. Ausencia de contacto directo entre estudiantes y docentes. Mientras en la educción presencial el estudiante tiene permanente contacto visual y físico con el docente, a quien puede manifestarle en algún momento de la clase aquellas dificultades e inquietudes que surjan durante el proceso de aprendizaje; en el aprendizaje remoto esto no es así. El docente está del otro lado de la plataforma y (en las videoconferencias) debe preocuparse por llegar, en el tiempo de clase previsto y de forma general, a todos los estudiantes. La comunicación personal de aquel con cada participante se ve limitada. Esta situación produce desmotivación en algunos estudiantes, quienes a pesar de las estrategias didácticas que implemente el docente o la calidad de los materiales y recursos disponibles en la plataforma, tienen una escasa o nula participación en las actividades y sienten la ausencia de aquel. En otras ocasiones, la falta de contacto agrava la situación porque los estudiantes tienen un limitado acceso a los medios informáticos debido a la brecha informática (Terán et al., 2019).

\section{Conclusiones}

La revisión sistemática de estudios realizados con relación al uso de las plataformas virtuales en la educación, permitió identificar trabajos que analizan la importancia de estas en educación. Asimismo, estas plataformas virtuales facilitan el aprendizaje en la modalidad educativa a distancia; generan cambios significativos en el proceso de enseñanza-aprendizaje. En algunos casos se usan las plataformas que tienen una versión gratuita, pero con ciertas limitaciones en sus funciones, o una versión comercial con acceso irrestricto a todas las funcionalidades.

En estos tiempos, las exigencias tecnológicas obligan a una constante actualización. A causa de ello, el docente necesita ser un agente innovador, enfrenta el reto de seleccionar y utilizar variadas estrategias que le ayuden en su labor pedagógica, por lo que debe ver a la plataforma como un excelente aliado que facilitará su trabajo.

A su vez, los estudiantes necesitan entender que la plataforma les ofrece acceso a las mismas actividades que realizaban en forma presencial, solo que ahora participan de una experiencia mejorada, con herramientas interactivas y materiales que fueron seleccionados pensando en un aprendizaje de calidad. Blackboard les ofrece una nueva experiencia de aprendizaje; abre ante ellos un abanico de posibilidades permitiéndoles ejecutar acciones individuales en actividades que incitan su creatividad y los obligan a pensar en forma reflexiva y crítica. Al mismo tiempo, se involucran en actividades colaborativas que no solo estimulan la interacción académica, sino que enriquecen sus relaciones interpersonales y profesionales.

La plataforma Blackboard ofrece diferentes herramientas que hacen novedosa su implementación, atractivos los contenidos y muy interactiva la relación entre docentes y estudiantes. Los foros, la retroalimentación, la presentación de trabajos y las evaluaciones en línea con sus respectivas retroalimentaciones son aspectos a valorar y tomar en cuenta. El aprovechamiento óptimo de estas funciones tiene impacto en el aprendizaje de los estudiantes. Estos cuentan con el acompañamiento y monitoreo del docente tutor, responsable de diseñar en forma interactiva el aula virtual, siguiendo parámetros cognitivos que aseguren la construcción de los saberes.

Es importante programar en forma idónea los contenidos del aula virtual usando todas las herramientas que brinda la plataforma, pues de ello depende la motivación e interacción del estudiante con los videos, archivos de audio, documentos, actividades, enlaces y materiales. Si se les motiva de manera apropiada, los estudiantes tendrán ganas de profundizar en el estudio de los temas propuestos. Estas actividades de fácil acceso favorecen la construcción del conocimiento. La retroalimentación del docente, aumentará el interés en los estudiantes y los compromete con 
el desarrollo de las actividades propuestas. Téngase presente que en cada estudiante dormita un repertorio de habilidades que deben activarse para involucrarlas en actividades retadoras que pongan a prueba capacidades y desarrollen competencias.

Se puede afirmar que la plataforma Blackboard genera mucha expectativa en las instituciones educativas. Su aprovechamiento en el proceso de enseñanza-aprendizaje virtual es una excelente alternativa para acortar las distancias entre las instituciones educativas y la comunidad, entre el docente y los estudiantes. Los aproxima enriqueciendo la interacción académica y ofreciéndoles nuevas posibilidades para el ejercicio de la pedagogía y el aprendizaje. Su implementación y uso dependerá mucho de los parámetros institucionales y el perfil académico que se ofrece a los beneficiarios del servicio educativo. Lo que está en juego realmente es el aprendizaje, la calidad del servicio y la formación de personas que desean recibir una educación de calidad.

Además en tiempos tan cambiantes en el que las tecnologías priman, la exploración de nuevas formas de enseñanza-aprendizaje debe ser una actitud constante en docentes que aman su profesión y lo que hacen cada día en mejoras de la calidad de la formación de los estudiantes que desean aprender superando cualquier limitación y dejando atrás las formas convencionales de acceder al conocimiento, debido a que el aprendizaje remoto con mediación de una plataforma virtual es tal vez el modelo educativo de este siglo XXI.

\section{Agradecimiento}

Un especial agradecimiento por el apoyo al desarrollo de este estudio, como parte del proyecto PIPD, Innovación docente y uso de las Tecnologías de la Información y Comunicación en el proceso de enseñanza aprendizaje con Resolución de Dirección Académica No. 012 2020-DA-UCV. Cabe destacar también que el estudio forma parte del programa de formación de recursos humanos, adscrito a la "Mentoría: Formación de nuevos investigadores en CTI, UCV" y a la Coordinación del Doctorado en Educación en la Modalidad Semipresencial de la Escuela de Posgrado de la Universidad César Vallejo, en el semestre 2020-II.

\section{Referencias Bibliográficas}

Almenar, V., Fernández, R., Maldonado, M. y Melguizo, C. (2019). El uso de Blackboard Collaborate como herramienta para la mejora de los espacios de comunicación en la enseñanza online de la Economía [ponencia]. V Congreso Internacional sobre Aprendizaje, Innovación y Competitividad (CINAIC), Madrid, España. https://doi. org/10.26754/CINAIC.2019.0133

Álvarez, M., Fernández, N., García, P., Grandoli, M., y Pérez, C. (2020). La docencia en el nivel de posgrado en el contexto de virtualización de emergencia. Aprendizajes y desafíos para el futuro en la experiencia de la Universidad Nacional de Tres de Febrero. Innovaciones Educativas, 22 (Especial), 171-187. https://doi.org/10.22458/ie. v22iEspecial.3153

Aguilar, W., De las Fuentes, M., y Rivera, R. (2019). Percepción de los estudiantes acerca de la modalidad Semipresencial en a Enseñanza de las Ciencias Básicas de la Ingeniería. Un estudio de caso universitario. Formación Universitaria, 12(83), 15-28. https://doi.org/10.4067/S071850062019000300015

Aguilar, I., Alejo, V., \& Ayala, J. (2020). Development of learning objects for the learning of data structures. Journal of Technology and Education Innovation, 6(1), 42-55.

https://doi.org/10.24310/innoeduca.2020. v6i1.5297

Barrera, V., y Guapi, A. (2018). La importancia del uso de las plataformas virtuales en la educación superior. Atlante Cuadernos de Educación y Desarrollo. Revista Atlante: Cuadernos de Educación y Desarrollo (en línea), https://www. eumed.net/rev/atlante/2018/07/plataformas-virtuales-educacion.html

Barrera, A., Peña Sklyar, I., \& Peña Matos, M. (2016). Diseño e implementación de un Entorno Virtual de Aprendizaje (EVA) utilizando la plataforma educativa Moodle. Estudio de caso: 
asignatura Ergonomía. Universidad de Cienfuegos, Cuba. Revista Universidad y Sociedad, 8(2), 33-40.

Blackboard Inc. (2020). Blackboard Collaborate Online Collaboration Tools That Engage Everyone, Every Time, Everywhere. http://www.blackboard.com/Platforms/Collaborate/Overview. aspx.

Campos, M., Menéndez, V., y Zapata, A. (2019). MITS: sistema de tutoría inteligente para asistir al profesorado en el uso de MOODLE. Innovación Educativa, 19(81), https://link.gale.com/ apps/doc/A610419232/IFME? $\mathrm{u}=$ univcv\&sid=IFME\&xid $=\mathrm{c} 4 \mathrm{cb} 8 \mathrm{cea}$

Cornejo, J., Limaymanta, C., Mezarina, R., \& Gálvez, B. (2020). Digital Portfolio in The Development of Documentary Competence in University Students. Revista Eduser, 7(2), 95-109. https:// doi.org/10.18050/eduser.v7i2.2541

De la Cruz, M. A., Macías, G. G., Viejó, J. L., y Chisag, J. C. (2020). Las plataformas virtuales para fomentar aprendizaje colaborativo en los estudiantes del bachillerato. Recimundo, 4(4), 199212. https://doi.org/10.26820/recimundo/4.(4). octubre.2020.199-212

De la Iglesia, M. C. (2019). Huellas de los estudiantes en las plataformas virtuales. Aplicación para evaluar una metodología de aprendizaje activo. Revista Electrónica Interuniversitaria de Formación del Profesorado, 22(3), 173-191.

https://doi.org/10.6018/reifop.371341

De Pablos, J., Bravo, M. P., López-Gracia, A., y Lázaro, I. (2019). Los usos de las plataformas digitales en la enseñanza universitaria. Perspectivas desde la investigación educativa. REDU: Revista de Docencia Universitaria, 17(1), 15.

https://doi.org/10.4995/redu.2019.11177

Escobar, A. (2017). Plataformas Virtuales de Aprendizaje en la Educación Superior. Revistas interconectando saberes, (4), 83-100.

García, L. (2020). Bosque semántico: ¿educación/enseñanza/aprendizaje a distancia, virtual, en línea, digital, eLearning...? Revista Iberoamericana de Educación a Distancia, 23(1), 09-28. https://doi.org/10.5944/ried.23.1.25495

Gil, J., y Martínez, J. (2018). El empoderamiento del alumnado en los sMOOC/[en] The students empowerment in the sMOOC. Revista Complutense de Educación, 29(1), 43.

https://doi.org/10.5209/RCED.51932

González, M.A., Perdomo, K.V. y Smith, O.Y. (2017). Aplicación de las TIC en modelos educativos blended learning: Una revisión sistemática de literatura. Sophia, 13(1), 144-154. https://doi. org/10.18634/sophiaj.13v.1i.364

Help Blackboard. (2021). Navegadores compatibles. Recuperado de https://help.blackboard. com/es-es/Learn/Student/Getting_Started/ Browser_Support

Hernández, C., y Tecpan, S. (2017). Aula invertida mediada por el uso de plataformas virtuales: un estudio de caso en la formación de profesores de física. Estudios pedagógicos (Valdivia), 43(3), 193-204. https://doi.org/10.4067/S071807052017000300011

Iglesias, R., y Soca, E. (2017). El empleo de herramientas web en el proceso docente educativo para informatizar procesos inteligentes de aprendizaje 4.0. Revista Cubana de Informática Médica, 9(2), 135-143. http://scielo.sld.cu/pdf/rcim/ v9n2/rcim05217.pdf

Lima de Castillo, W., Ribeiro, S.R., Barduchi, R.I., Antar, M., y De Oliveira, M.A. (2020). Módulo educativo en ambiente virtual de aprendizaje en Diabetes Mellitus. Enfermería Global, 19(59), 345-388. https://doi.org/10.6018/eglobal.320631 Lora, J. (2019). El Uso de Plataformas Virtuales para el Aprendizaje [tesina de grado de Ingeniero en Informática]. Universidad Politécnica de Sinaloa, México. http://repositorio.upsin.edu.mx/ formatos/952016030031LoraPeinadoJoseManuel6023.pdf

Martínez, G.A. y Jiménez, N. (2020). Análisis del uso de las aulas virtuales en la Universidad de Cundinamarca, Colombia. Formación Universitaria, 13(4), 81-92.

https://doi.org/ 10.4067 / S 0718 50062020000400081

Mora, E. R., Bonilla, D.M., Núñez, L.A. \& Sarmiento, J.C. (2018). Inadaptability of teachers to the management of virtual platforms: Educarecuador case. Conrado, 14(62), 39-43. http:// scielo.sld.cu/scielo.php?script=sci_arttext\&pi$\mathrm{d}=$ S1990-86442018000200006\&lng=es\&tlng=en 
Morales, M.G., Moreno, K.C., Romano, M.M. y García, M.R (2020). Gestión del conocimiento a través de plataformas y herramientas digitales de aprendizaje ante la migración de clases presenciales en línea. Revista GEON, 7(2), 1-19. https://doi.org/10.22579/23463910.217

Mulet, M. T., y Flores, E. F. (2019). Consideraciones para el diseño del proceso de enseñanza-aprendizaje de la asignatura Sistici, con el uso de las tecnologías de la información y las comunicaciones. REFCalE: Revista Electrónica Formación y Calidad Educativa, 7(1), 29-42.

Piedra, I. D., Eraña, I. E., Segura-Azuara., Hambleton, A., \& López, M. V. (2019). Designating criteria for educational technology assessment. Revista Médica, 20(2), 109-113. https://doi.org/10.1016/j.edumed.2018.04.020

Remache, A. P., Puente, E., y Moreno, G. A. (2017). Uso de las tecnologías de la información en la educación superior. INNOVA Research Journal, 2(1), 99-112.

https://doi.org/10.33890/innova.v2.n1.2017.154

Savio, K. (2020). La plataforma Moodle en la alfabetización académica: Uso del aula virtual en un taller de lectura y escritura. Páginas de Educación, 13(1), 1-18.

https://doi.org/10.22235/pe.v13i1.1923

Santivañez, B. S. (2019). Aplicación de la plataforma virtual LMS para mejorar el programa de capacitación laboral en el Colegio Particular Andino-Huancayo 2019 [tesis de maestría]. Universidad Nacional del Centro del Perú. Repositorio institucional.

Terán, L., Arano, E. del C., Maldonado, U., y González, A. J. (2019). Plataforma virtual para reforzar el proceso de acreditación en las Facultades del Área de Humanidades. Virtual platform to strengthen the accreditation process in the $\mathrm{Fa}$ culties of the Humanities Area. Revista Electrónica Sobre Tecnología, Educación Y Sociedad, 6(11). https://www.ctes.org.mx/index.php/ctes/ article/view/691

Tixi, D. L., Quinde, S. P., Chunata, N. M., \& Niama, M. P. (2019). Uso De Plataformas Virtuales de Aprendizaje en el Desarrollo Cognitivo de Estudiantes de Nivel Superior. European Scientific Journal, 15(13), 327-343. https://doi. org/10.19044/esj.2019.v15n13p327

Vargas, A.L., y Villalobos, G. (2018). El uso de plataformas virtuales y su impacto en el proceso de aprendizaje en las asignaturas de las carreras de Criminología y Ciencias Policiales, de la Universidad Estatal a Distancia de Costa Rica. Revista Electrónica Educare, 22(1), 20-39. https://doi. org/10.15359/ree.22-1.2

Herrada, R. I., y Baños, R. (2018). Aprendizaje cooperativo a través de las nuevas tecnologías: una revisión. @ tic. Revista d'innovació educativa, (20), 16-25.

https://doi.org/10.7203/attic.20.11266

Valenzuela-Zambrano, B., y Pérez-Villalobos, M.V. (2015). Aprendizaje autorregulado a través de la plataforma virtual Moodle. Educación y Educadores, 16(1), 66-79. ISSN: 0123-1294. https://doi.org/10.5294/edu.2013.16.1.4

Villalón, R., Luna, M., y García, A. (2019). Valoración y uso de la plataforma Blackboard Collaborate en una universidad a distancia: estudio de caso sobre las prácticas declaradas de docentes del Grado de Psicología. Digital Education, 35. http://greav.ub.edu/der/

Viñas, M. (2017). Importancia del uso de plataformas educativas. Letras, 1(6), 157-169. http:// www.memoria.fahce.unlp.edu.ar/art_revistas/ pr.8497/pr.8497.pdf 